\title{
EVOLUCIÓN DE LA POLÍTICA TURÍSTICA Y LA INTERVENCIÓN ESTATAL. EL CASO DE MARRUECOS ${ }^{1}$
}

\author{
Fernando Almeida García \\ Samia Chahine \\ Universidad de Málaga
}

\section{RESUMEN}

El turismo ha ido ganando espacio en la agenda política del gobierno de Marruecos. Durante los últimos 50 años, el desarrollo turístico ha estado liderado por el Estado, con diferentes grados de implicación, dependiendo del periodo y contexto político y económico. Se han alternado periodos de gasto público con otros de privatización o desinterés. Este trabajo presenta la evolución de la política turística de Marruecos, destacando el cambio de función que ha tenido el turismo que ha pasado de tener un papel secundario, a ser en la actualidad una pieza clave de la economía del país. Así mismo, se detalla el proceso de crecimiento turístico experimentado en los últimos años, similar al que han realizado otros países turísticos en vía de desarrollo. Este estudio analiza los principales planes turísticos llevados a cabo por el la Administración pública, y plantea un debate en torno al modelo actual de desarrollo turístico y su conexión con las inversiones internacionales y el sector inmobiliario.

Palabras claves: Política turística; Gobierno; Inversiones; Desarrollo; Marruecos.

Recibido: 21 de enero de 2015

Devuelto para su revisión: 4 de junio de 2015

Aceptado: 24 de septiembre de 2015

Departamento de Geografía. Universidad de Málaga. Campus de Teatinos. 29071 MÁLAGA (España). E-mail: falmeida@uma.es

1 Este trabajo está financiado por el Proyecto del programa de Investigación Fundamental No Orientada, «Geografías de la crisis: análisis de los territorios urbano-turísticos de las islas Baleares, Costa del Sol y principales destinos turísticos del Caribe» (CSO2012-30840). 


\title{
Evolution of Tourism Policy and state intervention: the case of Morocc
}

\begin{abstract}
Tourism has been gaining space on the political agenda of the government of Morocco. Over the past 50 years, tourism development has been led by the State, with different levels of involvement, depending on the period and political and economic context. In the Moroccan public policy have alternated periods of public spending with other privatization or neglect. This paper presents the development of tourism policy in Morocco, highlighting the role change that has taken the tourism in recent years, has become a key player in the economy, while in the past played a secondary role. Also, it is explained the process of tourism growth in recent years, similar to other tourist countries have made in developing. This study analyses the main tourist plans carried out by the Moroccan government, and open debate on the current model of tourism development connected with international investments and real estate.
\end{abstract}

Keywords: Tourism; Tourism policy; Government; Investments; Development; Morocco.

\section{INTRODUCCIÓN}

En este trabajo se analiza la evolución de la política turística de Marruecos, que ha pasado de ser un factor secundario en el desarrollo económico del país, a tener un papel predominante en los últimos años. Si bien desde el año 2000 la política turística es un elemento central en el proceso de desarrollo y modernización de Marruecos, esto no siempre ha sido así. En los años posteriores a la independencia (1956-1961) no se planteó una clara política turística; había un mayor interés por desarrollar otros «sectores productivos». Durante el largo reinado de Hassan II (1961-1999) se alternaron periodos de claro apoyo al turismo con otros de estancamiento y abandono. Pero nunca el turismo fue un elemento central en la política de desarrollo económico del país, tal y como sucedió en otros países norteafricanos próximos (Túnez y Egipto) y países europeos especializados en el turismo (España, Italia, etc.) (Hillali, 2007a; Almeida, 2012). A partir de 1999 con el reinado de Mohammed VI se ha producido un fuerte impulso del turismo, que se apoya en grandes planes de desarrollo (Vision 2010 y 2020) y medidas de atracción de inversión (Shamamba, 2005).

Este estudio debe entenderse como un análisis de una política pública, que en este caso es el turismo. La creación e impulso de la política pública está estrechamente relacionada con la función que desarrollan las administraciones públicas, que en este caso se centra fundamentalmente en el papel del Estado marroquí. No hay un acuerdo claro sobre qué es lo que se entiende por política pública: las hay muy generales² (Dye, 1992:2), otras detalladas ${ }^{3}$

2 «La política pública es lo que los gobiernos escogen hacer o no hacer».

3 «La política pública son todos las líneas de actuación llevadas a cabo por las autoridades. Así pues, política pública es lo que hacen dentro de sus funciones el presidente, gobernadores, primer ministro, ministros, parlamentarios, ... y demás miembros de la Administración». 
(Forward, 1974:1), de tipo instrumental ${ }^{4}$ (Anderson, 1984:3), en función de los actores ${ }^{5}$, (Jenkins, 1978:15) etc. Fenna (2004) propone una clasificación de las políticas públicas en función de los temas y objetivos hacia los que se dirigen las políticas. Este autor destaca (i) las políticas relacionadas con la producción, enfocadas hacia el incremento de actividad económica y el nivel de vida de la población; (ii) las políticas vinculadas con la distribución de la riqueza y la oportunidad de acceso; (iii) las políticas de consumo de bienes, servicios y recursos con una estrecha relación con el medio ambiente; (iv) las políticas relacionadas con la identidad y la ciudadanía, y por último, (v) las políticas reflexivas, que explican los procesos de realización de las políticas y la regulación y control de las mismas. El análisis que se presenta estaría más próximo a la primera tipología de políticas. De forma general, la mayor parte de los autores a la hora de describir los componentes de las políticas públicas coinciden en destacar el papel de los organismos públicos, la existencia de unos objetivos y problemas, el marco o ambiente en el que se desarrolla la política, los actores, la creación de instrumentos y los efectos de los mismos (Anderson, 1984; Pal, 1992; Dye, 1992; Considine, 2005; Hall, 2008; Velásquez, 2009; Scout, 2011). Buena parte de estos elementos los encontramos en el modelo de análisis propuesto en este trabajo.

Así mismo, este estudio sobre la política turística de Marruecos está acorde con numerosas investigaciones que resaltan el importante papel de los Estados en la elaboración de la política turística y la estrecha relación con el proceso de desarrollo económico (Hall, 1994:29). Este tema ha tenido un amplio espacio en los estudios turísticos y económicos (Hall y Jenkins, 1995; Monfort, 2000). Estos análisis se han preocupado más por destacar los logros de la política económica y turística, tales como la mejora de la balanza de pagos o la creación de empleo (Jenkins, 1980; Williams y Shaw, 1988; Hall, 1994) que los desequilibrios territoriales y sociales (Lea, 1988). Las limitaciones para generar desarrollo contrastan con las alabanzas que realizan los gobiernos sobre el papel que el turismo juega en el desarrollo económico nacional y regional (Lamb, 1998). Algunos autores señalan que el turismo tiene una limitada capacidad para general desarrollo en los países en vía de desarrollo (Britton, 1982) y que tienden a mantener las diferencias de renta entre los países centrales y los países en desarrollo (Blázquez, Cañada y Murray, 2011).

De forma general, la investigación sobre la política turística se ha centrado en países concretos, como parte de la política nacional (Lickorish, 1991). La consecución del desarrollo socioeconómico a través del turismo depende de una variedad de elementos y situaciones que escapan al control del propio sector. Muy diversos factores juegan un papel clave en este proceso: el contexto económico, social, político, geográfico y tecnológico o el medio ambiente en el que el turismo se desenvuelve. La mayoría de los estudios coinciden en que el nivel de desarrollo de un país, su tamaño geográfico, la tasa de crecimiento de la actividad turística, el grado de adaptación social a los cambios, la intervención del Estado y la existencia de la planificación del turismo son los principales factores en la determinación de su nivel de desarrollo y crecimiento económico (De Kadt, 1979; PabloRomero y Molina, 2013; Pearce, 1991).

\footnotetext{
4 «Las políticas públicas son las políticas desarrolladas los organismos oficiales y gubernamentales».

5 «Un conjunto de decisiones interrelacionadas tomadas por actores políticos o grupos de actores relacionadas con la selección de los objetivos y los medios para alcanzarlos dentro de una situación especial en la que estas decisiones deber quedar dentro de la capacidad de control de estos actores».
} 
Tabla 1

DATOS BÁSICOS SOBRE EL SECTOR TURÍSTICO DE MARRUECOS

\begin{tabular}{|c|c|c|c|c|c|c|}
\hline & 1991 & 1995 & 2000 & 2005 & 2010 & 2013 \\
\hline $\begin{array}{c}\text { Turistas } \\
\text { internacionales }\end{array}$ & 4.162 .000 & 2.602 .000 & 4.278 .000 & 5.843 .000 & 9.228 .000 & 10.046 .000 \\
\hline$\%$ Turistas de Europa & 57,4 & 81,7 & 82.7 & $44,6^{*}$ & $44,6^{*}$ & - \\
\hline Estancia media (días) & 4,0 & 7,5 & 6,9 & 6,3 & 7,7 & - \\
\hline Alojamiento (plazas) & 116.171 & 122.956 & 127.829 & 124.270 & 120.039 & - \\
\hline $\begin{array}{c}\text { \% ocupación por } \\
\text { plazas }\end{array}$ & 37,0 & 45,8 & 52,0 & 38,0 & 35,0 & $31,0 * *$ \\
\hline $\begin{array}{c}\text { Gasto tur. inter. } \\
\text { (millones \$) }\end{array}$ & 1.050 & 1.304 & 2.039 & 4.610 & 6.702 & 6.850 \\
\hline$\%$ Turismo sobre PIB & 4,0 & 4,0 & 6,8 & 9,1 & 8,9 & $8,7 * *$ \\
\hline
\end{tabular}

* No incluye a los marroquíes residentes en el extranjero ** Datos de 2012.

Fuente: OMT (1991-2013), Hillali, 2007 (PIB, 1991-95).

\section{Gráfico 1}

\section{EVOLUCIÓN DE LA LLEGADA DE TURISTAS} INTERNACIONALES A MARRUECOS

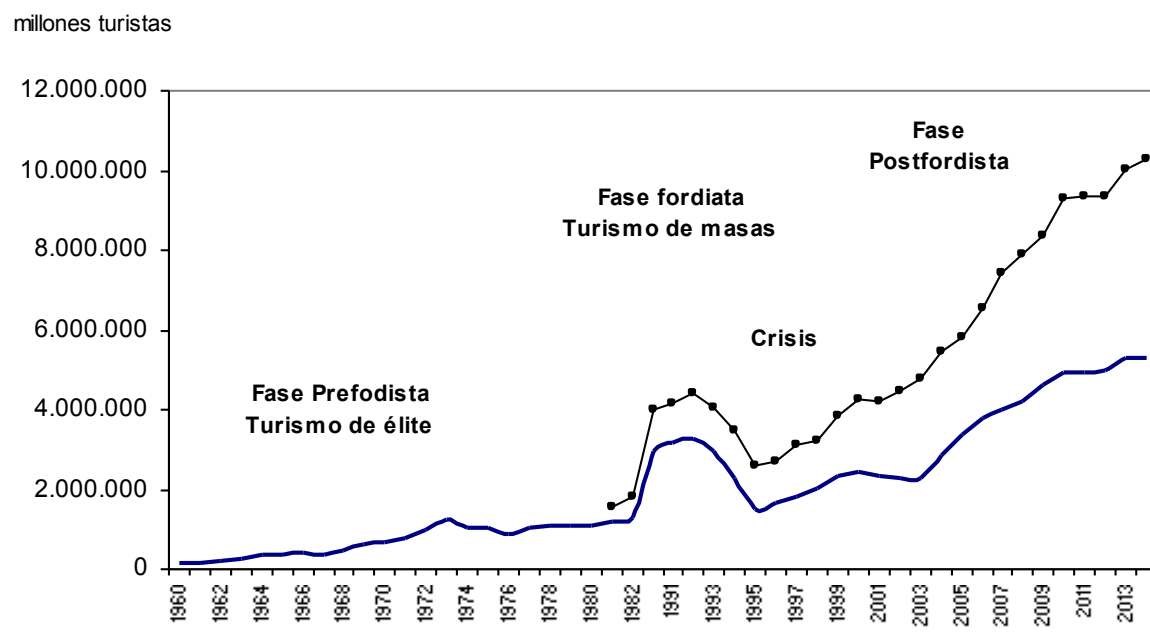

Turistas Extranjeros (Ministerio Turismo Marr.) $\multimap$ Turistas internacionales (OMT)

Fuente: Hilali, 2007, Ministère du Tourisme y OMT.

Nota: En los turistas extranjeros no se incluye a los marroquíes con otra nacionalidad y que residen fuera del país. 
Marruecos con 10,2 millones de turistas en el año 2015 se mantiene como el primer destino de África en recepción de turistas y el tercero por ingresos tras Sudáfrica y Egipto (OMT, 2015). Estas cifras responden a un fuerte crecimiento que se ha registrado en los últimos diez años. Ha mantenido una línea de crecimiento a pesar de las recientes turbulencias políticas que han afectado a otros países turísticos del norte de África, en especial a Túnez y Egipto (este último ha sido tradicionalmente el principal destino turístico en África). En la actualidad el turismo tiene un importante peso en la economía marroquí. Entre 2010 y 2013 los ingresos generados por el turismo internacional supusieron alrededor del 6,5\% del PIB (OMT, 2014; CIA, 2014). En resumen, en los últimos quince años, Marruecos ha experimentado un significativo cambio en la estructura económica, siendo el turismo el principal factor de desarrollo económico de Marruecos.

\section{OBJETIVOS Y METODOLOGÍA}

Este estudio analiza las tres fases principales en las que se ha dividido la política analizada: prefordista o artesanal, fordista y postfordista (Enríquez et al., 2012; Fayos-Solá, 1996; Garay y Cánoves, 2011). En cada una de las fases, se observa que los gobiernos han tenido una relación variable y particular con el sector turístico; no se puede decir que se haya producido un crecimiento continuo de la actividad turística desde la independencia de Marruecos en 1956. Este estudio se interesa por el papel jugado por el Estado en la construcción de la política turística, junto con el análisis de las consecuencias en el proceso de desarrollo del país. Estas fases en la política están acordes con los ciclos productivos de acumulación capitalista y del propio sistema productivo (Dunford, 1990).

Los objetivos específicos de este trabajo son: en primer lugar, estudiar las fases de la política turística de Marruecos; en segundo lugar, identificar el papel que el gobierno marroquí ha tenido en el reciente proceso de desarrollo económico nacional y en tercer lugar, examinar los principales programas y planes turísticos relacionados con el sector turístico. Así mismo, este estudio plantea una reflexión sobre los cambios en los modelos de desarrollo basado en el turismo y abre un debate concreto sobre el desarrollo económico dentro del modelo turístico postfordista, en el que la inversión inmobiliaria juega un papel esencial.

Metodológicamente este estudio utiliza el enfoque institucional para analizar la política de Marruecos (Scott, 2011) y adopta el modelo de análisis del proceso de construcción de la política turística propuesto por Hall (1994:49-50), realizándose una descripción secuencial de las fases. El enfoque institucional entiende que el turismo está fuertemente influido por la acción de gobierno y se interesa por la organización del poder y su relación con la política, así como por la creación de normas e incentivos. Dentro de este enfoque, este trabajo se encuadra en torno al debate sobre la teoría de la regulación, marco de referencia que tiene uno de sus focos principales de investigación en la relación entre el capitalismo y las formas de producción y acumulación fordista y postfordista (Rullán, 2008). La descripción secuencial permite el estudio de la evolución histórica de la política turística, como se ha realizado en otros trabajos (Velasco, 2004). El análisis de Hall se basa en una serie de variables principales que considera claves para entender una política concreta: contexto, decisiones políticas, impactos de las políticas, necesidades de implantación de políticas, 
etc. El análisis se ha hecho para cada periodo con las principales variables, recogiéndose en cuadros. El estudio se completa con un breve estudio de caso para la tercera fase de la política turística.

El método de trabajo que se ha aplicado, en primer lugar parte del análisis documental de los principales textos y planes relacionados con la política turística de Marruecos y de la revisión bibliográfica vinculada con el marco teórico en el que se enmarca el estudio. En segundo lugar, se ha utilizado diversas fuentes estadísticas, destacando los datos proporcionados por la Organización Mundial del Turismo y el Ministerio de Turismo de Marruecos.

\section{EVOLUCIÓN DE LA POLÍTICA TURÍSTICA EN MARRUECOS}

\subsection{La fase prefordista y fordista}

El inicio del turismo se puede situar en 1929 con la construcción del lujoso hotel La Mamounia en Marrakech. Las primeras iniciativas para difundir el turismo en Marruecos se deben al Mariscal francés Lyautey, que procuró ofrecer algunos lugares de descanso para los franceses y los turistas de élite (Chahine, 2010). Por ello, las inversiones fueron orientadas a la construcción de hoteles de lujo (como por ejemplo el hotel Palais Jamai en Fez, 1929) con el fin de adecuarse a las exigencias de los viajeros. El turismo comenzó en Marruecos durante el período del Protectorado, ya que tanto el protectorado francés como el español estuvieron interesados en la promoción del país, prueba de ello, es que Marruecos heredó más de 200 hoteles del periodo colonial (Berriane, 2009; Araque y Crespo, 2010).

Tras la independencia en 1956, el Estado se enfrentó a numerosos retos para organizar el país. Uno de los principales desafíos fue la creación de una estructura productiva propia, que rompiera la dependencia económica y generara empleo. En los primeros años hubo cierto debate en torno al modelo a seguir, socialista o capitalista (Hillali, 2007b). En esas fechas, las actuaciones del gobierno socialista de Naser en Egipto, tenían mucho atractivo en el mundo árabe. Pero el modelo de desarrollo se inclinó hacia el capitalismo liberal, y se optó por la planificación indicativa que estaba muy extendida entre los países del Mediterráneo norte (Portugal, España, Francia, Italia, Grecia, etc.) (Williams y Shaw, 1988; Almeida, 2012). La planificación indicativa se impuso en los países en vías de desarrollo como un requisito «recomendable» para recibir los créditos del Banco Mundial, a la vez que se daba seguridad a la inversión internacional y servía como documento base del proceso de desarrollo del país (Ramos y Pires, 2008). Los sectores hacia los que se dirigió la inversión pública en los años 60 y 70 fueron fundamentalmente la agricultura e infraestructuras hidráulicas y secundariamente la industria. Inicialmente, el turismo no se consideró un verdadero sector productivo y recibió una escasa inversión (Hillali, 2007a).

En los dos primeros planes de desarrollo económico (1958-1959 y 1960-1964), la inversión que se reservó para el turismo fue escasa (Tabla 2). Esta se dirigió hacia las ciudades históricas de Marruecos y a algunos complejos turísticos en el norte. De todos modos, hay que señalar un elemento que rompió esta situación: la creación del núcleo 
turístico de Agadir. En 1960 esta población sufrió un devastador terremoto que arrasó la ciudad. Para paliar la situación, el gobierno convirtió Agadir en un gran destino turístico y a diferencia de las tradicionales Ciudades Imperiales (Fez, Meknes y Marrakech), esta nueva ciudad se destinó al turismo de masas de sol y playa.

\section{Tabla 2 \\ INVERSIÓN PÚBLICA \\ EN EL SECTOR TURÍSTICO DE MARRUECOS}

\begin{tabular}{|c|c|c|c|}
\hline $\begin{array}{c}\text { Plan } \\
\text { Económico }\end{array}$ & $\begin{array}{c}\text { \% Inversión / Total } \\
\text { Presupuesto }\end{array}$ & $\begin{array}{c}\text { Plan } \\
\text { Económico }\end{array}$ & $\begin{array}{c}\text { \% Inversión / Total } \\
\text { Presupuesto }\end{array}$ \\
\hline $1958-1959$ & 0,2 & $1973-1977$ & 6,5 \\
\hline $1960-1964$ & 1,4 & $1978-1980$ & 3,4 \\
\hline $1965-1967$ & 6,4 & $1981-1985$ & 1,8 \\
\hline $1968-1972$ & 6,8 & $1988-1992$ & 1,2 \\
\hline
\end{tabular}

Fuente: Hillali, $2007^{\mathrm{a}}$.

En 1965 se aprobó el Plan Trienal de Desarrollo Social y Económico que apostó de una forma algo más decidida por el turismo (Tabla 2). Al turismo se le encomendaron diversas funciones «clásicas» como la obtención de divisas para la financiación de los programas de desarrollo, generación de empleo, captación del ahorro local y atracción de las inversiones extranjeras. En teoría el gobierno pretendía que el turismo no fuera únicamente un sector auxiliar, útil para el equilibrio de la balanza de pagos sino que desempeñara un papel clave en el desarrollo, incluso se creó en 1965 un Ministerio de Turismo para acompañar el proceso. En la práctica, el grueso de las inversiones públicas siguió yendo a la agricultura, infraestructuras hidráulicas y formación de cuadros técnicos. Además este Plan dio lugar a una pléyade de organismos públicos relacionados con el turismo que más bien dificultaron el proceso e incrementaron el poder de «el Madjen»6 (Hillali, 2007a:232-234).

El Plan Trienal creó una serie de figuras de desarrollo regional destacando las Zonas de Ordenación Prioritaria (ZAP). Para su aplicación se eligieron las zonas con mayores recursos turísticos situadas en áreas desfavorecidas del norte (Tánger, Alhucemas y costa de Tetuán) y del sur (Agadir y el eje Ouarzazate-Errachidia). Inicialmente la intervención estatal fue elevada, prueba de ello es que el Estado subvencionó el 95\% de las plazas creadas en las ZAP del norte (Hillali, 2007a). El programa de ajuste económico de los 90 y el fuerte déficit que acumularon estos organismos, dio lugar a su cierre y privatización en esa década.

Para mejorar y ampliar la oferta de alojamiento turístico, el Estado impulsó la creación de alojamientos estatales. La gestión fue encomendada a diversos organismos públicos y semi-públicos, destacando la Oficina Nacional Marroquí de Turismo (ONMT), la Caja de Depósito y de Gestión (CDG), la Sociedad Marroquí de Desarrollo Turístico (SOMADET), Maroc-Tourist, etc. (El Haddadi, 2010). La ONMT se encargó de diversas tareas

6 Élite política y económica del país. 


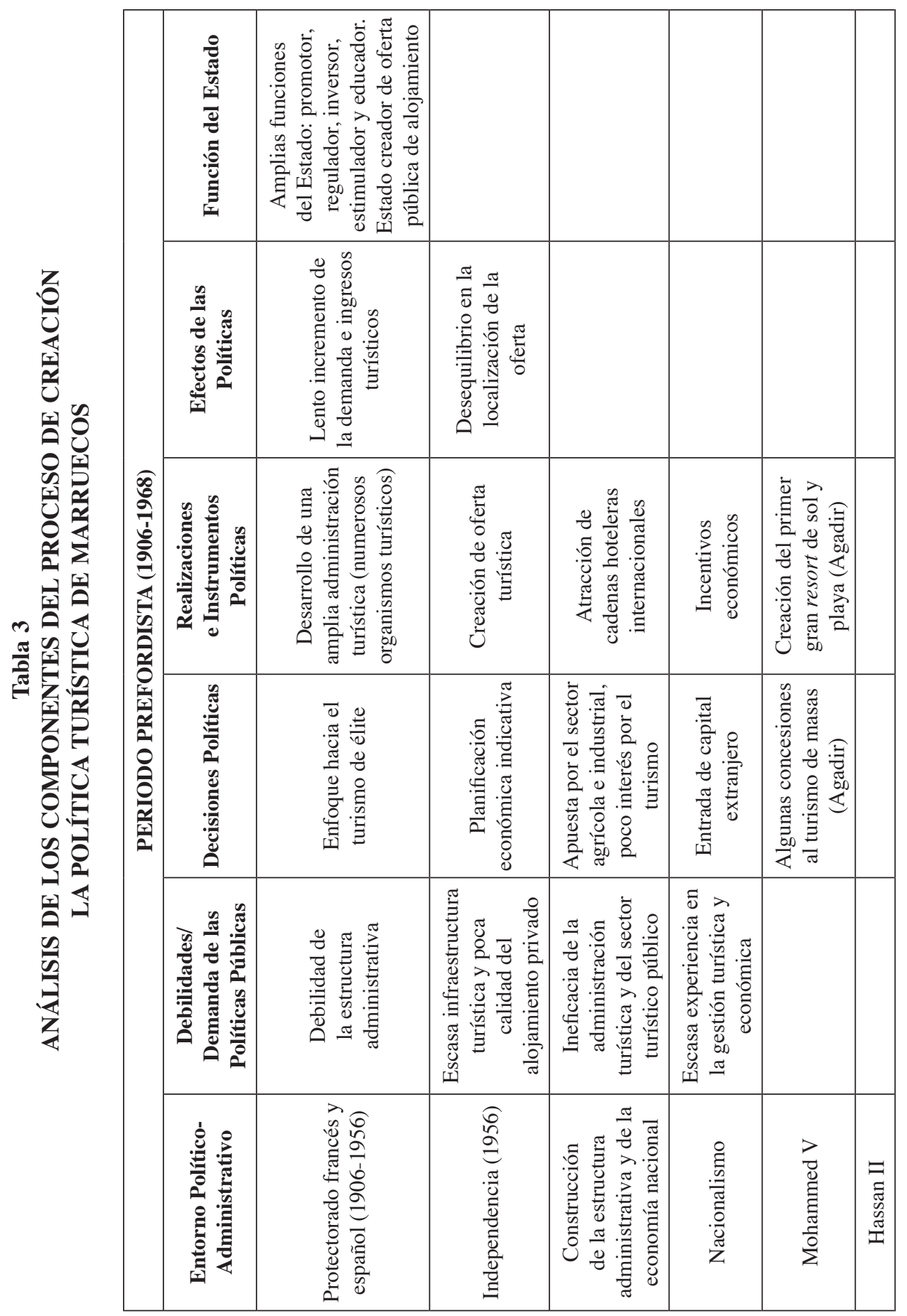


como la promoción turística y la organización de viajes, interviniendo muy directamente en la creación de alojamiento turístico. En 1976 llegó a gestionar 20 establecimientos turísticos con 4.526 plazas, constituyéndose en la primera cadena hotelera marroquí. Posteriormente muchos de estos hoteles y villas fueron privatizados. La CDG era una sociedad nacional de inversión que enfocó su actividad hacia la construcción de hoteles en las zonas menos desarrolladas del país.

En esta década, además de la fuerte intervención pública también hay que señalar la entrada de capital extranjero privado, destacando la cadena francesa Club Mediterranée que construyó seis complejos turísticos vacacionales en Marruecos. El primero de ellos fue el Club Med de Alhucemas inaugurado en 1964, al que siguió el de Agadir en 1965. En 1985, los ocho Club Med sumaban un total 4.170 plazas (Hillali, 2007a).

Plan quinquenal 1968-1972 siguió insistiendo en la ampliación de la oferta de alojamiento. Si en los anteriores planes el esfuerzo inversor se dirigió hacia hotelería de más calidad, en este Plan las actuaciones se concentraron en la gama media acorde al turismo de masas que se pretendía atraer. El Estado puso en marcha grandes proyectos de ordenación urbanística y territorial destinados a alojar grandes cantidades de turistas. Para la gestión de estos proyectos se crearon la Sociedad Nacional de Ordenación de la Bahía de Agadir (SONABA) y la Sociedad Nacional de Ordenación de la Bahía de Tánger (SNABT), que se sumaron a los anteriores organismos (El Haddadi, 2010).

Durante todo el periodo 1965-1972, el Estado fue el principal agente sustentador de la política turística, ya que asumió el $80 \%$ de las inversiones en el sector turístico. De todos modos, hay que poner en contexto esta cifra, ya que el turismo sólo supuso el 6,6\% del total de la inversión pública entre 1965 y 1972. Por otro lado, junto a la inversión directa, el Estado creó otros instrumentos financieros para dinamizar el sector: se establecieron subvenciones e incentivos (Normas de Inversión de 1960, 1973 y 1983), y se impulsó el crédito inmobiliario y hotelero. A modo de ejemplo, en este periodo el Estado garantizó cerca de $75 \%$ del coste de inversiones en operaciones de carácter turístico, mediante exoneraciones fiscales y crédito hotelero.

Tanto el Plan quinquenal de 1973-1977 como el Plan trienal de 1978-1980 tuvieron como objetivo principal el favorecer el turismo de masas. Entre uno y otro plan el contexto social y económico varió significativamente debido a los graves problemas económicos provocados por la Crisis del Petróleo, la caída de los precios del fosfato y la crisis política derivada de la anexión del Sahara Occidental. El porcentaje de inversión durante estos dos planes económicos en actividades turísticas se redujo significativamente. Un aspecto llamativo fue la escasa capacidad para la realización efectiva de los alojamientos programados por el sector público y semipúblico en el Plan quinquenal (sólo 4.200 sobre las 14.000 plazas previstas). El sector privado logró una ejecución del $70 \%$ de las previsiones. La iniciativa privada aprovechó el crédito y los incentivos económicos para la construcción de segunda residencia, de forma similar a lo que estaba sucediendo en España en el mismo periodo: el sector privado había perdido interés por la construcción hotelera en favor de la vivienda turística y la actividad inmobiliaria en general (Esteve y Fuentes, 2000). Los destinos con menor inversión pública tuvieron un mejor funcionamiento en comparación con la zona norte mediterránea en la que se concentró buena parte de la inversión turística pública y que obtuvo unos resultados pobres (Hillali, 2007a:130). 
La retirada de la inversión estatal en las actividades turística fue lo habitual en los siguientes planes. En esa línea, el Estado aportó una inversión reducida en el Plan quinquenal 1988-1992 y sus actuaciones se enfocaron hacia nuevos productos turísticos (segunda residencia, turismo de montaña). Uno de los sucesos más destacables fue la fuerte caída de los turistas extranjeros en 1994, hecho que se relaciona con el atentado terrorista de Marrakech, además de los efectos de la I Guerra del Golfo (Berriane, 2009; Moudoud y Ezaïdi, 2005) (Gráfico 1). En este contexto negativo de pérdida de demanda junto a los problemas económicos internos, se aprobó la Ley Marco 18/95 que limitó las ayudas públicas destinadas al turismo. El programa de ajuste económico impulsado por el Banco Mundial para Marruecos obligó a una fuerte reestructuración del sector turístico que ya arrastraba graves dificultades económicas, ocasionadas por el estancamiento de la demanda extranjera en los años noventa (Gráfico 1). Acorde al Plan de Ajuste, en 1990 se inició el proceso de privatización de las sociedades públicas turísticas, dando lugar a la venta de la mayor parte de los establecimientos turísticos públicos. Para tal fin se creó un ministerio para la privatización. Se pusieron en venta 37 hoteles de 4 y 5 estrellas que fueron adquiridos por cadenas internacionales y nacionales (Ouahidi y Mzidabi, 1994).

\title{
Tabla 4 \\ PRINCIPALES HECHOS DESTACADOS DE LA POLÍTICA TURÍSTICA MARROQUÍ
}

\author{
1918 Creación del Comité Central de Turismo (la actual ONMT) \\ 1960 Reconstrucción de Agadir \\ 1964 Suscripción de un Acuerdo Turístico entre los Gobiernos de Marruecos y España \\ 1965 Creación del Ministerio de Turismo \\ 1965 Plan Trienal (1965-1697). El turismo como una de las prioridades \\ 1968 Creación de la SONABA y de la SNABT \\ 1978 Plan Trienal (1978-1980). Fuerte reducción de la inversión estatal en el turismo. \\ 1988 Plan Quinquenal (1988-1992). Expansión de la demanda \\ 1990 Aprobación del Plan de Ajuste. Inicio del proceso de privatización \\ 1994 Fuerte caída en la demanda turística \\ 2001 Acuerdo Marco 2001-2010/ Vision 2010 \\ 2007 Creación de la SMIT \\ 2010 Nuevo plan turístico: Vision 2020 \\ 2011 Creación del FMDT
}

En definitiva, a lo largo de los años 60 y 70, el Estado intervino como planificador, inversor, promotor y constructor, para impulsar la actividad turística nacional; en los años 80 y 90 se produce una reducción de la inversión turística y la privatización de alojamientos; con el nuevo siglo el Estado recuperó el papel del turismo como dinamizador económico y con una función importante en la agenda política. 


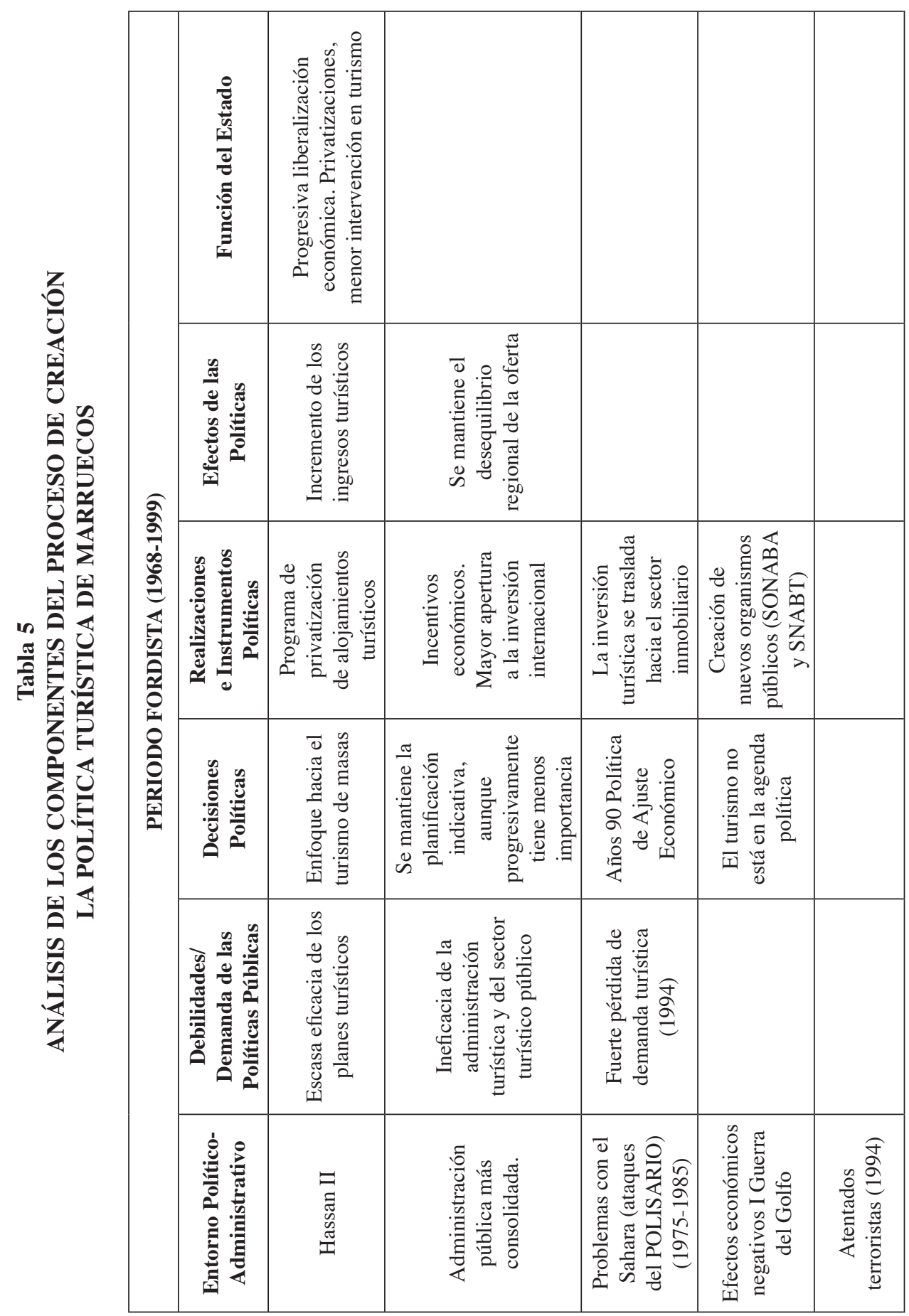

Cuadernos de Turismo, 38, (2016), 13-37 


\subsection{La Fase postfordista. El Plan Vision 2010}

Con la llegada al trono de Mohammed VI en 1999 se produjo un cambio de rumbo en la política turística de Marruecos (Araque y Crespo, 2010). El turismo se convierte en uno de los ejes principales del desarrollo económico del país, y el Estado plantea como objetivo principal la conversión de Marruecos en un país turístico. Para conseguir este objetivo, los poderes públicos enfocaron este desarrollo turístico de una forma clásica: creación de una serie de planes turísticos estratégicos, atracción de inversión internacional, liberalización del espacio aéreo, incentivos económicos y facilidades para la creación de grandes resorts turísticos-inmobiliarios destinados principalmente al mercado europeo (Chahine, 2010; Almeida, 2011). En este proceso ha jugado un papel muy importante la captación de las inversiones internacionales, tanto europeas como del golfo Pérsico, destinadas al alojamiento hotelero y en gran medida al turismo residencial. En esta fase de la política turística el Estado se convierte en un agente inversor destinado a captar capitales internacionales y a servir como avalista para la construcción de los grandes resorts e infraestructuras turísticas. Por otro lado, el gobierno acomete una importante labor de desregulación de sectores económicos vinculados al turismo, en especial el sector aéreo y realiza un elevado gasto en infraestructuras destinadas al sector turístico.

En 2001 en Marrakech se celebró un importante encuentro del sector turístico en el que se presentó un gran plan turístico nacional: el Plan Vision 2010, documento que marca el inicio del cambio de política turística. Este Plan se organiza en torno a seis ejes principales: producto, transporte, formación, comercialización y promoción, organización institucional y entorno turístico, siendo el más importante el eje de producto que supone la mayor parte de las actuaciones del Plan y que tiene un presupuesto de 4.840 millones de dólares (Ministère du Tourisme, 2015a). Las principales actuaciones del Plan son la creación de nuevos productos turísticos y estaciones turísticas. Se articula mediante cuatro grandes planes:

- Plan Azur: Plantea la construcción de seis estaciones turísticas litorales dirigidas cada una a un segmento de mercado específico. Estas instalaciones reciben el apoyo financiero del Fondo Hassan II. El modelo seguido es el de los grandes resorts del Caribe y Asia. Los complejos turísticos propuestos son: Mediterrania-Saidía, Mazagan Beach Resort, Port Lixus, Mogador Essaouira, Taghazout-Argana Bay y Plage Blanche-Guelmin.

- Plan Biladi: Este plan tiene como estrategia desarrollar ocho complejos turísticos destinados al turismo interno, mediante un alojamiento turístico con unos precios asequibles.

- Plan Mada'In: Se trata de consolidar, reforzar y poner en valor los antiguos destinos turísticos tanto los que ofrecen un turismo cultural, como los de sol y playa o mixtos.

- Plan de Turismo Rural: Se pretende desarrollar el turismo rural y consolidar la actividad turística en el medio rural, ofreciendo alojamiento adecuado, animaciones locales e itinerarios planificados. 
Es un plan de fuerte crecimiento turístico a corto plazo que pretendía alcanzar grandes cifras en menos de diez años, en 2010. Los objetivos principales planteados por el Plan fueron los siguientes (Ministére du Tourisme, 2015a):

(a) Atraer 10 millones de turistas en 2010 .

(b) Hospedar a 7 millones de turistas internacionales en hoteles y alcanzar una capacidad de alojamiento de 230.000 camas.

(c) Construir 6 grandes complejos turísticos.

(d) Conseguir una entrada de divisas de 8.873 millones de dólares.

(e) Crear 600.000 nuevos empleos directos.

(f) Dar formación a 72.000 profesionales de turismo.

(g) Aumentar el porcentaje de gasto turístico sobre el PIB desde el 6.5\% al 8.0\%.

El balance de este Plan pone de relieve que se han alcanzado algunas de las grandes cifras económica: se consiguió que el gasto turístico supusiera el $8 \%$ del PIB en 2010; en 2010 llegaron 9.3 millones de turistas internacionales a Marruecos (aunque la mitad son marroquíes residentes en el extranjero); los ingresos por turismo estuvieron próximos al objetivo (6.702 mill.\$). En cambio, hay objetivos que claramente no se han cumplido (Traspaderne, 2011). No se ha realizado la oferta de alojamiento prevista en el Plan Vision 2010 y sus planes específicos: Plan Biladi y Plan Azur. El Plan Biladi está orientado a la demanda nacional y su misión era la de construir un número importante de instalaciones turísticas de las que sólo hay una abierta. El Plan Azur era un ambicioso programa de creación de grandes resorts de sol y playa, que ofertaría 80.000 plazas. De los seis grandes resorts que ocuparían más de 2.500 has., sólo han abierto sus puertas dos: Saidía y Mazagan. Este Plan se ha visto muy afectado por la crisis económica mundial de 2008, que ha sido más intensa en Europa, espacio originario de muchas de las empresas inversoras en este Plan (España, Francia, Bélgica) (Gil de Arriba, 2011).

Además, Vision 2010 planteaba una reorganización de la estructura administrativa ligada al turismo. El principal cambio ha sido la creación de una nueva entidad, «Sociedad Marroquí de Ingeniería Turística» (SMIT) dedicada a la planificación y las inversiones turísticas. Esta sociedad pública creada en 2007 ha reagrupado a tres empresas públicas: la Dirección de Adecuación y de Inversiones (DAI), y las sociedades de desarrollo de Agadir (SONABA) y de Tánger (SNABT). SMIT ha intervenido en el desarrollo de complejos turísticos del Plan Azur y Biladi, además de la captación de inversión internacional. A pesar de esta reducción burocrática, se mantiene un gran número de organismos públicos relacionados con turismo, además del propio Ministerio de Turismo (Ministère du Tourisme, 2015b).

\subsection{Política turística actual: El Plan Vision 2020}

En la misma línea de crecimiento turístico y búsqueda de capital internacional, se creó el Plan Vision 2020. Este Plan es una continuación de Vision 2010, aunque plantea unos objetivos aún más ambiciosos en búsqueda de la maximización de la actividad turística. El objetivo principal es lograr que Marruecos forme parte de los veinte mayores desti- 
nos turísticos del mundo. Con el fin de diversificar la oferta turística y abarcar todas las regiones del país, esta nueva «Vision» ha creado ocho territorios ${ }^{7}$ o regiones turísticas especializadas según sus recursos turísticos (Gráfico 2). Los principales objetivos de este Plan son los siguientes (Ministère du Tourisme, 2015c):

a) Duplicar la capacidad de alojamiento turístico, con la construcción de 200.000 nuevas plazas de los cuales, 150.000 son camas hoteleras y 50.000 son de otro tipo de alojamiento.

b) Duplicar el número de turistas internacionales para alcanzar 20 millones de turistas en el horizonte 2020.

c) Triplicar el número de viajes de los turistas nacionales, con el objetivo de democratizar el turismo en el país.

d) Crear 470.000 nuevos empleos directos.

e) Aumentar los ingresos por turismo hasta alcanzar los 15.500 millones de dólares en el horizonte 2020.

f) Incrementar la participación del PIB turístico en dos puntos dentro del PIB nacional.

Dentro del Plan Vision 2020, se han elaborado seis programas turísticos que coordinan las actuaciones turísticas que se llevan a cabo en las ocho regiones turísticas.

a) Azur 2020. Desarrollo de la oferta de sol y playa y de las regiones turísticas. Se mantiene la oferta de los grandes complejos turísticos.

b) Turismo Interno. Plan Biladi. Actuaciones enfocadas hacia el turismo nacional mediante ciudades de vacaciones y estaciones Biladi.

c) Eco-desarrollo sostenible. Creación de productos turísticos sostenibles. Turismo rural.

d) Patrimonio Cultural. Utilización del extenso patrimonio (funduks, kashbas, ryads, ksours, etc.)

e) Ocio y Deporte.

f) Negocio, Salud y Bienestar.

La realización de la Vision 2020 requerirá, acorde con las evaluaciones preliminares realizadas, la movilización de cerca 16.000 millones de euros en inversiones públicas y privadas, incluyendo el presupuesto para promoción, comercialización y formación, la inversión en infraestructuras, los incentivos a la inversión y la financiación bancaria nacional e internacional. Esta gran cantidad supone casi el 18.5\% del PIB del país en 2013 en términos nominales (CIA, 2015).

En los últimos años se ha producido algunos cambios en la gestión turística de los planes turísticos, provocados en última instancia por la crisis económica europea. El Estado en apoyo del Plan Vision 2020 ha creado una nueva institución pública destinada a facilitar la financiación y a acelerar la realización de los proyectos. Este nuevo órgano es el Fondo Marroquí de Desarrollo Turístico (FMDT). Es un fondo público de inversión, bajo la tutela

7 Los ocho territorios o regiones turísticas no son coincidentes con las regiones administrativas de Marruecos. La distribución se compone de dos regiones especializadas en turismo de sol y playa, cuatro regiones enfocadas al turismo cultural y dos regiones destinadas al turismo de naturaleza. 


\section{Gráfico 2 \\ COMPLEJOS TURÍSTICOS Y REGIONES. PLAN VISION 2020}

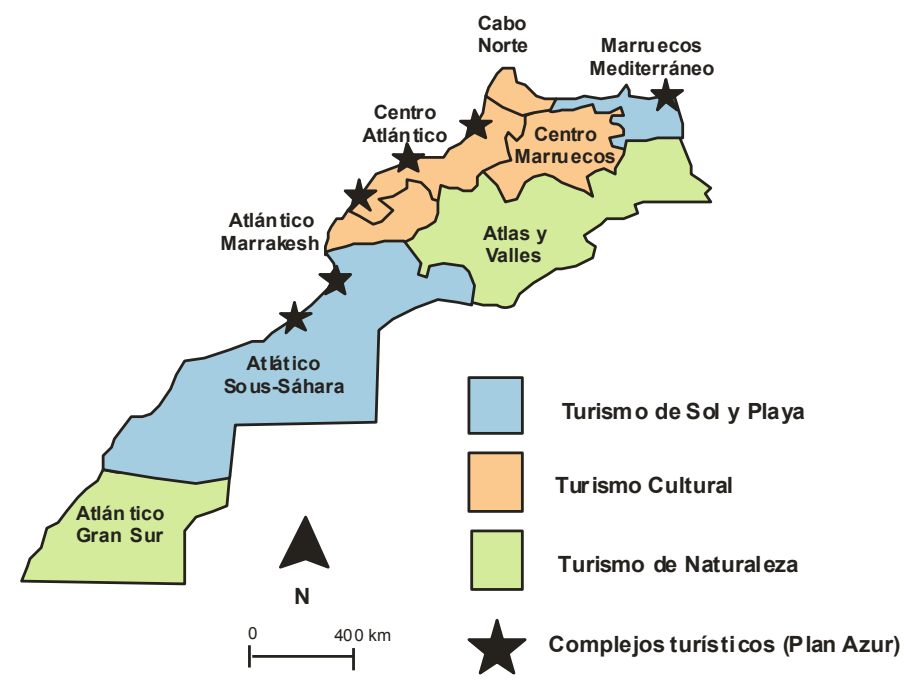

Fuente: elaboración propia.

del Ministerio de Turismo de Marruecos. Está constituido mediante una participación conjunta entre el Estado y el Fondo Hassan II con un capital de unos 1.660 millones de dólares para un periodo de 10 años. Este fondo se centra en la participación en empresas y desarrollo de proyectos turísticos estratégicos, incluyendo los grandes proyectos turísticos. Además, este fondo tiene como objetivos facilitar la financiación del sector turístico, buscar inversión internacional y orientar el ahorro público hacia el sector turístico. El FMDT es la puerta de entrada para los inversores nacionales e internacionales que desean invertir en sector turístico marroquí. Así mismo, se encarga de poner en contacto entre sí a los inversores y empresarios privados y públicos de Marruecos.

Las primeras participaciones del FMDT se han orientado hacia al reflotamiento de las estaciones turísticas del Plan Azur. El FMDT ha entrado en el nuevo reparto de acciones de los resorts de Saidía y Taghazout, haciéndose cargo del $30 \%$ y el $25 \%$ del accionariado respectivamente, conjuntamente con otras entidades públicas y privadas marroquíes del sector turístico e inmobiliario (CDG Développement ${ }^{8}$, Groupe Alliances ${ }^{9}$, Sud Partners ${ }^{10}$, SMIT, SDS ${ }^{11}$ ). El Estado a través del FMDT se ha hecho cargo del mantenimiento de estos proyectos del Plan Vision 2010, además de la terminación de los ya iniciados. Una rápida evaluación de los proyectos finalizados, muestra que la actuación no ha sido muy rentable para el Estado marroquí, tanto por los costes asumidos al comprar las acciones,

\footnotetext{
8 Filial de la Caja de Depósito y de Gestión.

9 Uno de los grandes grupos inmobiliarios del país.

10 Sud Partners es un consorcio de varios fondos marroquíes de inversión.

11 Sociedad de Desarrollo de Saidía, antigua Sociedad de Ordenación de Saidía (SAS).
} 
como por los elevados gastos realizados en la construcción de infraestructura (aeropuerto, abastecimiento y depuración de aguas, etc.), además de los importantes incentivos económicos concedidos a las empresas.

En el Plan Vision 2020 hay dos cambios significativos. Por un lado, ha irrumpido con fuerza los fondos internacionales en la financiación del Plan, y por otro lado, se ha producido un cambio en el origen de la inversión (Verdaguer, 2005; Shamamba, 2005). En el Plan Vision 2010 el capital internacional estaba ligado a grandes constructoras y cadenas hoteleras internacionales, procedentes principalmente de Europa (España, Francia y Bélgica), Estados Unidos y Sudáfrica, además de la empresas marroquíes; y además, el papel de los fondos internacionales de inversión era secundario. Por el contrario, en el Plan Vision 2020 predominan los fondos internacionales y tiene un fuerte peso los países del Golfo Pérsico.

Esta nueva situación se explica en parte por la grave crisis económica de los países europeos. Hasta el año 2008 hubo una importante inversión turística e inmobiliaria procedente de Europa y sobre todo España (García y Tasias, 2007; Saad, 2008). A partir de 2008 los países del Golfo Pérsico y otros países musulmanes son los que han venido a cubrir el hueco europeo en la inversión turística e inmobiliaria (Baabood, 2009). En 2009 el segundo inversor extranjero en Marruecos fue Kuwait con el 14,9\% y el cuarto Emiratos Árabes Unidos con un 5,9\%; en 2011 el primero seguía siendo Francia con el 37\% y el tercero España con 8,3\% (Gil de Arriba, 2011). El mejor ejemplo de lo comentado es la creación del fondo de inversión Wessal Capital, establecido entre Marruecos y los países del Consejo de Cooperación del Golfo. Wessal Capital es un consorcio de cuatro fondos soberanos originarios de Kuwait, Emiratos Árabes Unidos, Qatar y Marruecos creado en 2011. Dispone de un capital de 2.000 millones de euros, lo que lo convierte en uno de los mayores fondos de inversión de África (FMDT, 2012). Buena parte de sus inversiones están destinadas a la financiación de proyectos turísticos estratégicos de Marruecos. Este fondo está constituido por (i) Al Ajial Investment Fund Holding, fondo de inversión de «Kuwait Investment Authority» (KIO); (ii) Aabar Investments PJS, una subsidiaria de la compañía «International Petroleum Investment» (IPIC), que es propiedad del Gobierno de Abu Dhabi; (iii) Qatar Holding LLC, el fondo soberano de inversión de «Qatar Investment Authority» y (iv) Fonds Marocain de Développement Touristique, el FMDT ${ }^{12}$ es el patrocinador marroquí de Wessal Capital. Otro fondo de inversión importante es ASMA. Este un fondo constituido entre Arabia Saudita y Marruecos, en el que participa el Estado de Marruecos y la Casa Real Saudí. Disponía de unos 500 millones de dólares destinados en parte a proyectos turísticos.

\subsection{Estudio del caso de Saidía}

Saidía es un pequeño pueblo costero de 3.338 habitantes en la costa mediterránea del nordeste de Maruecos, en la provincia de Berkane y muy próximo a la frontera con Argelia. En este área se localiza una de los seis grandes complejos turísticos previstos por el

12 El FMDT está invirtiendo en los complejos turísticos de sol y playa del Plan Azur para reflotar y relanzar estas actuaciones. 
Plan Vision 2010 y el Plan Azur. Este proyecto tenía previsto inicialmente la construcción de 9 hoteles con una capacidad de 17.000 plazas turísticas y 13.000 plazas de segunda residencia. Así mismo, se plantea la construcción tres campos de golf de 18 hoyos, un puerto deportivo, un parque acuático, helipuerto, centros comerciales, palacio de congresos, etc. Los estudios oficiales preveían que la actividad turística de la estación generaría unos 5,5 millones de pernoctaciones por año, unos beneficios brutos de unos 435 millones de euros y unos ingresos por impuestos y tasas de unos 240 millones de euros (Chahine, 2010). De todas las actuaciones, por ahora se han construido un puerto deportivo, un campo de golf, varios hoteles y una parte de la vivienda turística.

El complejo turístico de Mediterrania-Saidía se inició en 2003 mediante la adjudicación del proyecto por parte del Gobierno marroquí, a la empresa constructora española Fadesa dentro de un concurso ligado al Plan Azur (Plan Vision 2010). Esta constructora también se hizo con el encargo de otro resort del Plan Azur (Plage Blanque-Guelmin), pero abandonó este proyecto. Para llevar adelante el complejo turístico de Saidía estableció contactos con diversas cadenas hoteleras españolas (Barceló, Iberostar, Oasis y Riu) y la norteamericana Best Western. Fadesa se centró en el negocio inmobiliario (la construcción y venta de vivienda turística) y la construcción de hoteles e infraestructuras. La cercanía a España y Europa auguraba un gran negocio de venta de vivienda, de la misma forma que ya se ha había ensayado en España. Fadesa planteó una inversión inicial de unos 2.000 millones de euros. El Estado proporcionó el suelo a muy bajo precio, además de invertir en la construcción de carreteras y en la ampliación del aeropuerto de la cercana ciudad de Oujda ${ }^{13}$.

\section{Gráfico 3 \\ ENTORNO DEL COMPLEJO TURÍSTICO DE SAIDÍA (MARRUECOS)}

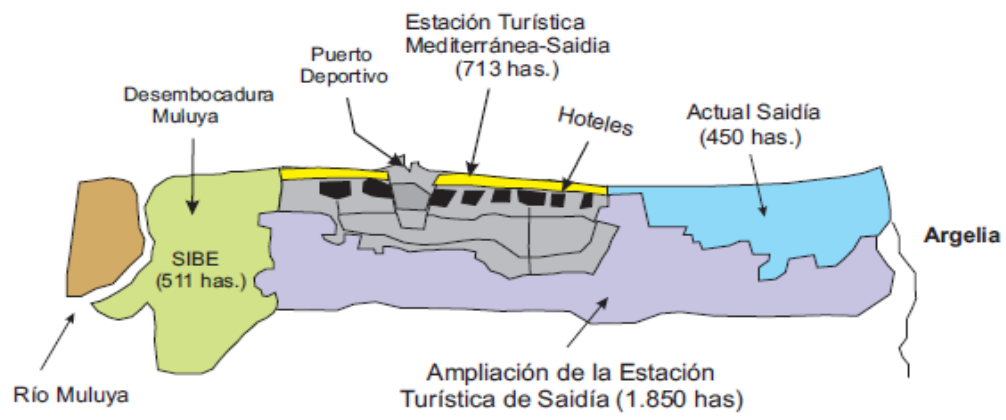

Fuente: elaboración propia.

La crisis económica de Europa y el estallido de la burbuja inmobiliaria en España, afectó gravemente a Fadesa, lo que obligó a vender sus participaciones a la empresa marro-

13 El aeropuerto se amplió en 2010 por 900 millones de dirham (83 mill.€) para que pudiera recibir 3 millones de pasajeros, aunque en 2014 sólo se recibieron unos 450.000 (Yibiladi, 2010). 


\begin{tabular}{|c|c|c|c|c|c|c|c|}
\hline \multirow{6}{*}{ 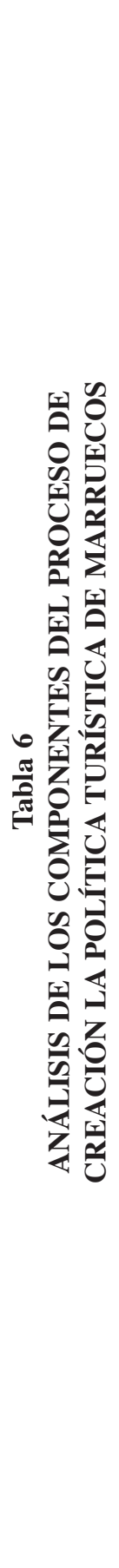 } & \multirow{6}{*}{ 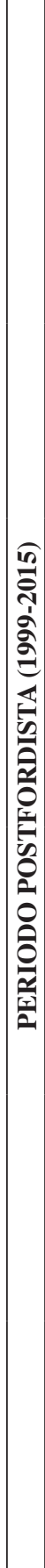 } & 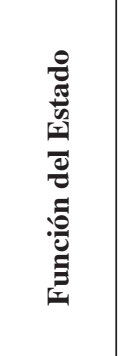 & 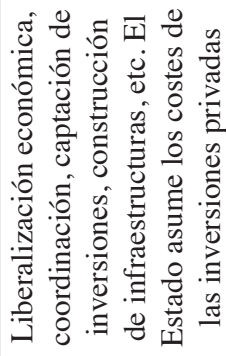 & & & & \\
\hline & & 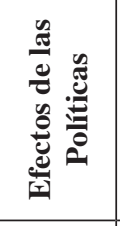 & 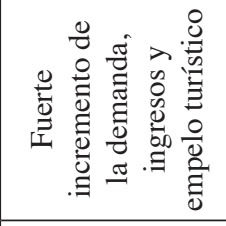 & 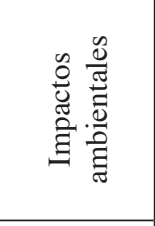 & 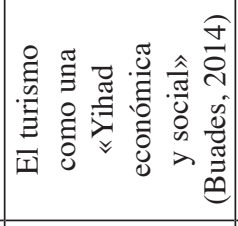 & & \\
\hline & & 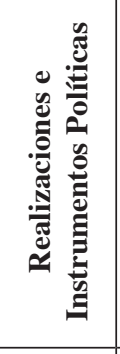 & 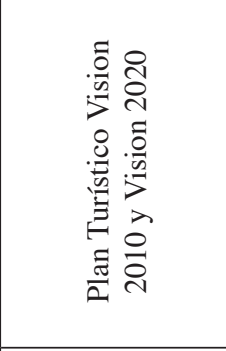 & 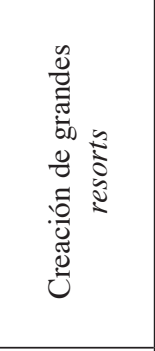 & 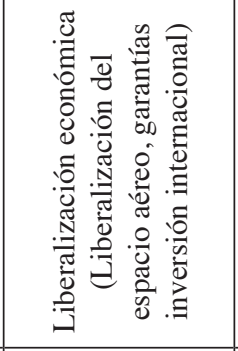 & 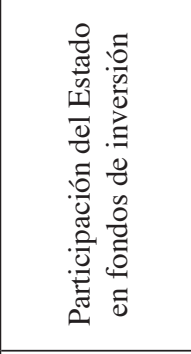 & 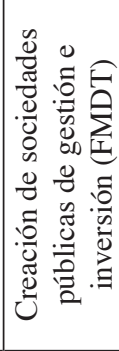 \\
\hline & & 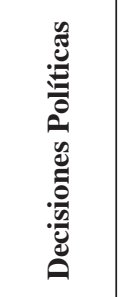 & 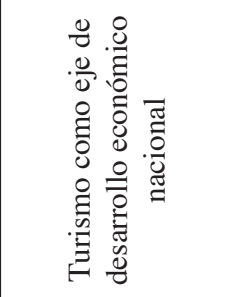 & 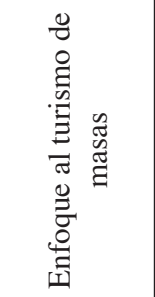 & 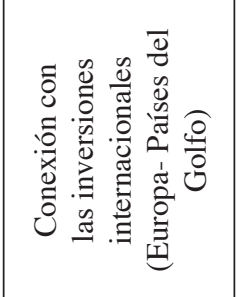 & 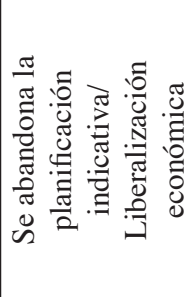 & 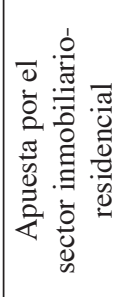 \\
\hline & & 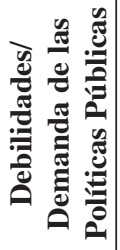 & 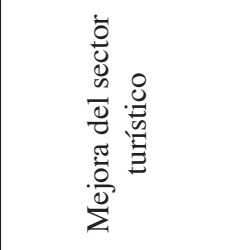 & 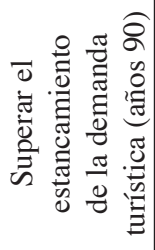 & 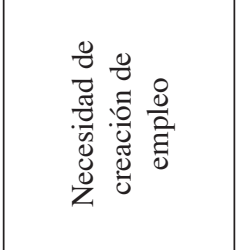 & & \\
\hline & & 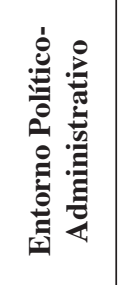 & 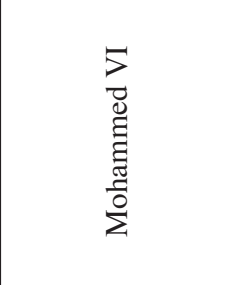 & 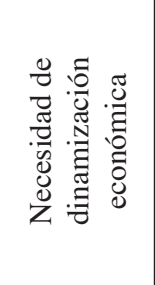 & 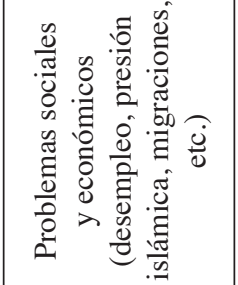 & 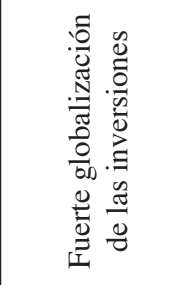 & 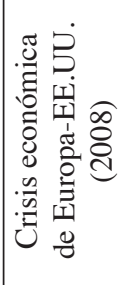 \\
\hline
\end{tabular}


quí Addoha ${ }^{14}$ en 2009. En ese mismo año el rey Mohammed VI inauguró oficialmente el complejo turístico, abriendo sus puertas el hotel Barceló Saidía de 5 estrellas y 1.200 plazas (Yrigoy, 2013). Con el rescate del proyecto, el Gobierno marroquí se ha comprometido a llevar a cabo la inversión prevista por Fadesa (2.190 mill. €). Para llevar adelante el proyecto, se ha buscado la participación de las empresas públicas marroquíes, de tal forma que la distribución actual del accionariado del complejo turístico es el siguiente: un $60 \%$ pertenece a CDG (Caja de Depósito de Gestión), 30\% FMDT (Fondo Marroquí de Desarrollo Turístico) y un $10 \%$ es de Addoha. Incluso el hotel Barceló de 5 estrellas fue vendido a Atlas Hospitality Morocco, filial de Royal Air Maroc (Chahine, 2012). Se puede decir que esta estación turística se ha convertido en un complejo público y que balance general presenta una más que dudosa rentabilidad económica para el Estado. A estas cifras económicas, el gobierno contrapone el impacto positivo del empleo: las obras de complejo Mediterrania-Saidía han creado 1.700 puestos de trabajo directos y 8.500 indirectos, esperando que cuando esté en pleno funcionamiento generen 8.000 puestos de trabajo directos y 40.000 indirectos (Yrigoy, 2013).

La construcción de este complejo que supera en extensión al de Marina D’Or en España, ha provocado diversos impactos ambientales. En primer lugar, se ha destruido y transformado el sistema dunar y su vegetación debido a la extracción de áridos utilizados para la edificación de la estación balnearia; además se ha alterado la deriva litoral de la zona a causa de la construcción del puerto Mediterránea-Saidía, uno de los proyectos estrella del complejo. Es preocupante la amenaza que se cierne sobre el espacio natural de la desembocadura del río Muluya, zona húmeda incluida en el convenio RAMSAR, cuyas aguas pretenden ser utilizadas para regar el campo de golf y para recibir las aguas residuales del complejo turístico (Araque, 2013; Boumeaza et al., 2010; Yrigoy, 2013).

\section{CONCLUSIONES}

Como se ha podido comprobar en la evolución de la política turística de Marruecos, el país ha experimentado un importante cambio en su relación con el turismo. El turismo ha pasado de ser un elemento casi residual a convertirse en un elemento central de la agenda política del país; y esto último ha sucedido con gran celeridad en los últimos quince años.

En la primera fase, durante el Protectorado y hasta fines de la década de los 60, el turismo estaba enfocado a un turista de élite y no era un asunto por el que el Estado mostrara gran interés. Después de la independencia en 1956, las inversiones estatales se dirigieron a proyectos industriales y agrícolas. A diferencia de otros países cercanos como Túnez, Marruecos no apostó por el turismo como factor de desarrollo. Se optó por un modelo clásico de inversiones en sectores «productivos», dentro del marco de los modelos de crecimiento regional y planificación indicativa, similar a los que se aplicaron en los países del sur de Europa (Portugal, España, Francia, Italia o Grecia) (Richardson, 1986).

14 Principal grupo inmobiliario que participa activamente en numerosos sectores económico de Marruecos y cercano a la élite política de Marruecos. Siguió con la venta de vivienda enfocada al mercado francés, en especial a los marroquíes residentes en el extranjero. Ha tenido diversas reclamaciones por falta de entrega de las viviendas en Saidía. 
Es en la segunda fase de la política turística, a comienzos de 1970, cuando empieza a crecer de forma significativa la actividad turística, tanto en los destinos culturales (las ciudades imperiales) como en el turismo de sol y playa de Agadir. Es el inicio del turismo de masas que registró un fuerte crecimiento en los años 80. En los años 90 se originó una fuerte caída que coincidió con diversos factores: crisis económica, atentado terrorista, proceso de privatización de la oferta, etc. (Gráfico 1). En esta etapa, durante el mandato del anterior monarca, Hassan II, el Estado marroquí, nunca consideró que el turismo fuera una pieza relevante para el desarrollo económico de Marruecos, aunque la inversión pública fuera significativa en algunos momentos. Un elemento de gran importancia que restó eficacia a la política turística de los gobiernos de Hassan II fue el complejo entramado de empresas turísticas públicas y semipúblicas que presentaban una mala gestión, dudosa rentabilidad y que sirvieron más bien para el mantenimiento de los intereses de grupos cercanos al poder (el Madjen) (Hillali, 2007a). Además, el entramado público restó capacidad de gestión y comercialización al sector turístico privado. A ello hay que añadir las reducidas posibilidades de inversión debido al ineficiente sistema fiscal y la fuerte intervención estatal en la economía (Verdaguer, 2005). La citada ineficacia del sector público junto con la presión del Fondo Monetario Internacional, dentro de un contexto de crisis, son factores que explican el proceso privatizador del sector turístico en los años 90. A partir de esa fecha se produjo una progresiva retirada de la iniciativa pública en el sector turístico.

En la tercera fase, desde el año 2000, el Estado se convierte en un verdadero dinamizador de la actividad turística y asume la mayor parte de las inversiones. Las Administraciones Públicas muestran un claro interés en apoyar el turismo y abrir el mercado turístico nacional hacia inversiones internacionales. Para ello, se ofrecen beneficios fiscales e incentivos a la inversión extranjera en el turismo, se liberaliza la economía (Open Sky), se atrae a los grandes fondos internacionales de inversión (Wessal) o se crean nuevos organismos nacionales de inversión y gestión (Fondo Marroquí para el Desarrollo Turístico). Pero esta liberalización no se acompaña de una retirada de la inversión pública, el Estado sigue aportando cuantiosos recursos naturales y financieros, lo que hace que el negocio sea muy rentable para el inversor extranjero. Se aplican recetas ya conocidas en otros países turísticos en vías de desarrollo, como fue España en los años 60 o en algunas islas del Caribe en los años 90 (Blázquez y Cañada, 2011; Almeida, 2012). Las estaciones turísticas promovidas por el Plan Azur guardan un notable parecido con los Centros de Interés Turístico Nacional desarrollados a lo largo de toda la costa española en los años 60 hasta los años 80. En general, el actual desarrollo turístico marroquí pasa por la misma situación que el desarrollo turístico español de los años 60. Con la experiencia de los efectos provocados, el Estado marroquí podría trabajar en minimizar los efectos negativos: fuerte impacto ambiental, excesivo peso de la oferta inmobiliaria, dependencia hacia los agentes turísticos e inversores externos, etc. (Araque, 2013; Galiana y Barrado, 2006).

En la fase post-fordista entran en juego otras variables, como la deslocalización y flexibilidad productiva, la búsqueda del segmento turístico y dos factores que cobran especial importancia en el caso de Marruecos: la intervención de los fondos internacionales de inversión, en muchos casos ajenos al sector turístico y la conexión con el sector inmobiliario. El factor inmobiliario tiene una singular importancia. En primer lugar, los 
nuevos planes turísticos presentan en su mayoría esa doble versión (turística e inmobiliaria). Pareciera que los complejos turísticos no van a funcionar si no hay promoción inmobiliaria. En segundo lugar, el Plan Vision 2010 nace durante el auge constructivo en Europa y en España, en particular, teniendo ambos hechos una estrecha vinculación. Este Plan iba a acoger parte de la expansión de la burbuja inmobiliaria europea y española. No es casualidad que Fadesa, una de las constructoras insignes de la burbuja inmobiliaria española, emprendiera dos de los megaproyectos turísticos de Marruecos. Posteriormente, el Plan Vision 2020 se ha conectado a la burbuja constructiva del Golfo Pérsico (Baabood, 2011).

Esta estrecha vinculación entre turismo y construcción hay que entenderlo dentro del concepto de solución espacio-temporal elaborado por Harvey (2003, citado en Arrighi, 2004). El exceso de producción de capital necesita tener una salida para mantener su rentabilidad y no generar inflación. Una magnífica solución es fijar al suelo este capital financiero por medio de vivienda turístico-residencial que genera unas tasas de rentabilidad mucho más elevada que la actividad hotelera convencional. La creación de espacios de sol y playa de carácter turístico-residencial es una magnífica solución para la acumulación de capital, y los planes como Vision 2010 y 2010 son inmejorables destinos para ese capital.

El balance general de los dos planes destaca ciertos éxitos que son indudables: el importante incremento de turistas (primer destino de África), ingresos por turismo (más de 7.000 mill.\$ en 2014) o el empleo creado (cerca de 500.000 empleos directos) (OMT, 2015: Ministére du Tourisme, 2015c); pero puede ser discutible la rentabilidad para el Estado si se tienen en cuenta todos los costes económicos, y más aún si se le suman posteriormente los costes ambientales y sociales. No podemos olvidar que este panorama es similar a los ya citados casos del Caribe o el Mediterráneo de décadas atrás (De Kadt, 1979; Jenkins, 1980; Britton, 1982; Lea, 1988). Estos autores señalaban que los modelos de desarrollo basados en el turismo que se ofrecían a los países en vías de desarrollo, se caracterizaban por un fuerte consumo de recursos naturales, poca innovación tecnológica, bajos sueldos, amplios incentivos a las empresas foráneas y elevada inversión estatal, etc., elementos que terminan generando una fuerte dependencia económica (Jenkins, 1980). Esta situación se podría estar repitiendo en Marruecos. En el caso estudiado de Saidía, los costes económicos asumidos por el gobierno marroquí, junto a las externalidades sociales y ambientales ponen en duda la rentabilidad general del modelo impulsado por la política turística de Marruecos. Este ejemplo estudiado, posiblemente sea extrapolable al resto de complejos turísticos impulsados por el gobierno de Marruecos y es acorde a situaciones ya criticadas en la década de los 70 y 80 para los países en vía de desarrollo (Lea, 1988) y que se mantiene en la actualidad pero a una escala global (Holden, 2013).

\section{BIBLIOGRAFÍA}

ALMEIDA, F. (2011): Transformaciones turísticas en el litoral mediterráneo marroquí. Madrid, Universidad Carlos III.

ALMEIDA, F. (2012): «La política turística de España y Portugal», Cuadernos de Turismo, $\mathrm{n}^{\circ}$ 30, pp. 9-34.

ANDERSON, J.E. (1984): Public Policy Making, New Cork, CBS College Publishing. 
ARAQUE, E. y CRESPO, J.M. (2010): «Tourisme, territoire et environnement sur la côte mediterranéenne du Maroc», Cahiers de la Mediterranée, $\mathrm{n}^{\circ}$ 81, pp. 331-348.

ARAQUE, E. (2013): «Desarrollo turístico y medio ambiente en la costa norte de Marruecos», Cuadernos de Turismo, no 31, pp. 13-30.

ARRIGHI, G. (2004): «Spatial and other fixes of historical capitalism», Journal of World Systems Research, Vol.10, $\mathrm{n}^{\circ}$ 2, pp. 527-539.

BAABOOD, A. (2009): La creciente presencia económica de los países del Golfo en la región mediterránea, Barcelona, Instituto Europeo del Mediterráneo (IEMED).

BAABOOD, A. (2011): La disminución de las inversiones de los países del Golfo en la región mediterránea, Barcelona, Instituto Europeo del Mediterráneo (IEMED).

BERRIANE, M. (2009): Tourisme des nationaux, tourisme des étrangers: Quelles articulations en Méditerraneé?, Faculté des Lettres et des Sciences Humaines de Rabat.

BLÁZQUEZ, M. y CAÑADA, E. (Coord.) (2011). Turismo placebo. Nueva colonización turística: del Mediterráneo a Mesoamérica y el Caribe. Lógicas espaciales del capital turístico, Managua, Enlace.

BLÁZQUEZ, M., CAÑADA, E. y MURRAY, I. (2011). Búnker playa-sol. Conflictos derivados de la construcción de enclaves de capital transnacional turístico español en el Caribe y Centroamérica, Scripta Nova, Revista electrónica de Geografía y Ciencias Sociales, XV (368).

BOUMEAZA, T., SBAI, A., SALMON, M. y OZER, A. (2010): «Impacts écologiques des aménagements touristiques sur le litoral de Saïdia, Maroc oriental», Mediterranée, $\mathrm{n}^{\circ} 115$, pp. 95-102.

BRITTON, S. (1982): «The political economy of tourism in the third world», Annals of Tourism Research, $\mathrm{n}^{\circ} 9$ (3), pp. 331-358.

BUADES, J. (2014): Exportando paraísos. La colonización turística del Planeta, Palma de Mallorca, Albasur.

CENTRAL INTELLIGENCE AGENCY (CIA) (2015): The World Factbook. Morocco. https://www.cia.gov/library/publications/the-world-factbook/geos/mo.html

CHAHINE, S. (2010): Desarrollo turístico del litoral mediterráneo de Marruecos. Saidía como destino. Facultad de Turismo. Universidad de Málaga.

CHAHINE, S. (2012): «Turismo globalizado en Marruecos: el caso de Saidía», Seminario Otras miradas, otros turismos, Facultad de Turismo, Universidad de Málaga.

CONSEDINE, M. (2005): Making public policy: institutions, actors, strategies. Cambridge, Polity Press.

DE KADT, E. (Ed.) (1979): Tourism: Passport to Development? Perspectives on the Social and Cultural Effects of Tourism in Developing Countries. New York: Oxford University Press.

DUNFORD, M. (1990): Theories of regulation, Society and Space, 8(3), 297-221.

DYE, T. (1992): Understanding Public Policy, Englewood Cliffs, Prentice-Hall.

EL HADDADI, H. (2010): El turismo interno en la península tingitana. "Una aproximación al análisis de la demanda y sus efectos económicos», Tesis doctoral inédita, Universidad de Granada. 
ENRÍQUEZ, M.A., OSORIO, M., CASTILlO, M. y ARELlANO, A. (2012): «Hacia una caracterización de la política turística», Pasos. Revista de Turismo y Patrimonio Cultural, $\mathrm{n}^{\mathrm{o}} 10$ (3), pp. 417-428.

ESTEVE, R. y FUENTES, R. (2000): Economía, historia e instituciones del turismo en España. Madrid, Pirámide.

FAYOS-SOLÁ, E. (1996): «Tourism policy: a midsummer night's dream?» Tourism Management, $\mathrm{n}^{\circ} 17$ (6), pp. 405-412.

FENNA, A. (2004) : Australian public policy, Sydney, Pearson Education Australia.

FONDS MAROCAIN DE DEVELOPPEMENT TOURISTIQUE (FMDT) (2012): 2 milliards d'euros pour Wessal Capital. Rabat, Pôle Investissement.

FORWARD, R. (1974): «Introduction», en Public Policy in Australia, FORWARD, R. (Coord.), Melbourne: Cheshire.

GALIANA, L. y BARRADO, D. (2006): «Los Centros de Interés Turístico Nacional y el despegue del turismo de masas en España», Investigaciones Geográficas, n 39, pp. 73-93.

GARAY L. y CÁNOVES, G. (2011): «Life cycles, stages and tourism history: The Catalonia (Spain) experience», Annals of Tourism Research, no 38 (2), pp. 651-671.

GARCÍA, L. y TASIAS, G. (2007): «Turismo y promoción inmobiliaria en Marruecos», Boletín Económico del ICE, n 2918, pp. 69-75.

GIL DE ARRIBA, C. (2011): «Del turismo hotelero al turismo residencial en Marruecos. Entre el negocio inmobiliario y la recreación de imaginarios socioespaciales», Cuadernos de Turismo, $\mathrm{n}^{\circ} 27, \mathrm{pp}$. 471-487.

HALL, C.M. (1994): Tourism and politics. Policy, power and place. London, Belhaven Press.

HALL, C.M. y JENKINS, J.M. (1995): Tourism and Public Policy, London and New York, Routledge.

HALL, C.M. (2008): Tourism planning. Policies, processes and relationships, London, Pearson Prentice Hall.

HILLALI, M. (2007a): La politique du tourisme au Maroc: diagnostic, bilan et critique, Paris, Harmatton.

HILLALI, M. (2007b): «Du tourisme et la géopolitique au Maghreb: Le cas du Maroc», Hérodote, $\mathrm{n}^{\circ} 127$, pp. 47-63.

HOLDEN, A. (2013): Tourism, poverty and development, London, Routledge.

JENKINS, W.I. (1978): Policy Analysis: A political and organizational perspective, London: Robertson.

JENKINS, C.L. (1980): Tourism policies in developing countries: a critique, en International Journal of Tourism Management, March, 22-29.

LAMB, A.N. (1998): Tourism development and planning in Australia-the need for a national strategy. Hospitality Management, $\mathrm{n}^{\circ} 7$ (4), pp. 353-361.

LEA, J. (1988): Tourism and development in the third World. London: Routledge.

LICKORISH, L.J. (1991): «Developing a single European tourism policy», en Tourism Management, September, 179-184.

MINISTÉRE DU TOURISME (2015a): Vision 2010, http://www.tourisme.gov.ma/fr/ vision-2020/vision-2010 (acceso 12/08/2015). 
MINISTÉRE DU TOURISME (2015b): Ministére du Tourisme, http://www.tourisme.gov. $\mathrm{ma} / \mathrm{fr} /$ administration-du-tourisme/organigramme (acceso 12/08/2015).

MINISTÉRE DU TOURISME (2015c): Vision 2020 en bref, http://www.tourisme.gov.ma/ fr/vision-2020/vision-2010 (acceso 12/08/2015).

MONFORT MIR, V. (2000): «La política turística: una aproximación», Cuadernos de Turismo, ${ }^{\circ} 6$, pp. 7-27.

MOUDOUD, B. y EZAÏDI, A. (2005): «Le tourisme national au Maroc: opportunités et limites de développement», Téoros, $\mathrm{n}^{\circ} 24$, pp. 1-10.

OBSERVATOIRE DU TOURISME (2010): Annuaire Statistique du Maroc, Rabat, Fédération Nationale du Tourisme et le Ministère du Tourisme.

ORGANIZACIÓN MUNDIAL DEL TURISMO (OMT) (2012): Compendium of Tourism Statistics. Madrid, OMT.

ORGANIZACIÓN MUNDIAL DEL TURISMO (OMT) (2014): Panorama del turismo internacional 2014. Madrid, OMT.

ORGANIZACIÓN MUNDIAL DEL TURISMO (OMT) (2015): Panorama del turismo internacional 2015. Madrid, OMT.

ORGANIZACIÓN MUNDIAL DEL TURISMO (OMT) (2016): Panorama del turismo internacional 2016. Madrid, OMT.

OUAHIDI, S. Y MZIDABI, S. (1994): L'impact de la privatisation sur le secteur touristique, Institut Superieur International du Tourisme de Tanger.

PABLO-ROMERO, M.P. y MOLINA J.A. (2013): «Tourism and economic growth: A review of empirical literature», Tourism Management Perspectives, $\mathrm{n}^{\circ}$ 8, pp. 28-41.

PAL, L.A. (1992): Public policy analysis: An introduction. Scarborough: Nelson Canada PEARCE, D. (1991): Tourist development. New York, John Wiley \& Sons.

RAMOS, J. y PIRES, L. (2008): «Los economistas españoles frente a la planificación indicativa del desarrollismo», IX Congreso de la AEHE, 27 de mayo de 2013. Universidad de Murcia.

RICHARDSON, H.W. (1986): Economía regional y urbana, Madrid, Alianza editorial.

RULLÁN, O. (2008): «Reconversión y crecimiento de las zonas turísticas. Del fordismo al postfordismo», en Destinos turísticos: viejos problemas, ¿nuevas soluciones? TROITIÑO, M.A., GARCÍA, J. y GARCÍA, M. (Coords.), pp. 587-626.

SAAD, Y. (2008): «Inversiones españolas por miles de millones en Marruecos: inmobiliario y turismo, sectores claves», Tendencias Económicas, Invierno 2007/2008, pp. 80-81. Afear/Ideas.

SCOTT, N. (2011): Tourism Policy: a strategic review, Oxford, Goodfellow.

SHAMAMBA, A. (2005): «Marruecos en la vía del turismo industrial», Tendencias Económicas, Invierno 2005, pp. 81-83, Afear/Ideas.

TRASPADERNE, L.Y. (2011): El sector del turismo en Maruecos, Informes sectoriales. Oportunidades de inversión y cooperación empresarial, Embajada de España en Rabat e Instituto Español de Comercio Exterior (ICEX).

VELASCO, M. (2004): La política turística: gobierno y administración turística en España (1952-2004), Valencia, Tirant lo Blanch. 
VELASCO, M. (2005): ¿Existe la política turística? La acción pública en materia de turismo en España (1951-2004). Política y Sociedad, nº 42 (1), pp. 169-195.

VELÁSQUEZ, R. (2009): «Hacia una definición del concepto «política pública», Desafíos, $\mathrm{n}^{\mathrm{o}} 20, \mathrm{pp} .149-187$.

VERDAGUER, E. (2005): «Turismo en Marruecos: retos y oportunidades», Economía Exterior, ${ }^{\circ} 33$, pp. 119-124.

WILLIAMS, A. y SHAW, G. (1988): Tourism and economic development. Western European experiences, London \& New York, Belhaven Press.

YIBILADI (07/12/2010) «Ouverture du nouveau terminal de l'aéroport d'Oujda.» http:// www.yabiladi.com/articles/details/3870/ouverture-nouveau-terminal-1-aeroport-doujda.htm (acceso 12/08/2015).

YRIGOY, I. (2013): «La urbanitzaó turística com a materialització de l'acumulació de capital hoteler», Treballs de Catalana de Geografia, n 75, pp. 109-131. 
